\title{
Três novos Phaneroptertdae brasileiros do gênero Hyperophora Brunner
}

\author{
S. DE TOLEDO PIZA \\ Professor de Zoologia da Escola Superior de Agricultura \\ "Luiz de Queiroz" da Universidade de S. Paulo
}

INDICE

Hyperophora simplicicauda sp. n. ....... 100

Hyperophora brevicauda sp. n. ......... 101

Hyperophora brevithorax sp. n. ........ 101 
Hyperophora simplicicauda sp. n. (Fig. 1)

Mas. Viridis. Caput viride, post oculos castaneo-rufo vittatum. Palpi maxillares et labiales articulis distalibus rufescentibus. Antennae nitidae, intus albae, extus castaneae, articulis I et II partim castaneo punctatis. Pronotum viride, disco parallelo, duplo longiore quam latiore, in medio longitudinaliter lineato, castaneo-rufo minutissime punctato, utrinque late castaneo-rufo vittato, lobis deflexis rotundatim insertis, perpendicularibus, multo longioribus quam latioribus et antice quam postice angustioribus, margine inferiore recto. Elytra viridia, longitudine pronoti vix angustiora, campo dorsali utrinque castaneo-rufo densiore vittato, parte suturali terrosa a vena ulnari posteriore alba confinata. Vena mediastina distincta, dimidium elytrorum haud attingens. Alae hyalinae, iridescentes, extremitatem elytrorum valde superantes. Femora antica viridia. Femora intermedia castanea diluta, apice viridi. Femora postica basi viridi, parte reliqua castaneo densiore. Tibiae castaneae. Segmentum abdominale dorsale primum superne in medio processu magno, obliquo, compresso, truncato, castaneonitido, armatum. Segmentum nonum truncatum, in medio longitudinaliter vix carinatum. Lamina supraanalis apice rotundato. Cerci cylindro-conici, extremitate attenuata et introrsum directa, apice modice ampliato et antice minutissime nigro dentato. Lamina subgenitalis inferne plana, obliqua, tricarinata, apice rotundatim bidentato, extremitatem cercorum vix attingente.

Longitudo corporis $\ldots \ldots \ldots \ldots \ldots \ldots, 17,5 \mathrm{~mm}$

Longitudo pronoti $\ldots \ldots \ldots \ldots \ldots \ldots, 4,0 \mathrm{~mm}$

Latitudo pronoti $\ldots \ldots \ldots \ldots \ldots \ldots \ldots, \mathbf{2 , 0} \mathrm{mm}$

Longitudo elytrorum .......... 28,5 $\mathrm{mm}$

Latitudo elytrorum ............. $3,5 \mathrm{~mm}$

Longitudo femorum posticorum ... 24,0 $\mathrm{mm}$

Pátria : Piracicaba, E. de S. Paulo, Bairro da Jiboia. Col. : Dr. Luiz Gonzaga E. Lordello, X-1949.

Tipo: Um macho, na coleção do autor.

A presente espécie caracteriza-se pelos cercos desprovidos de processo interno, pelos élitros de largura menor que o comprimento do pronoto, pelo processo dorsal do primeiro segmento abdominal e pelo nono segmento do abdômen truncado e apenas carinado. 
Hyperophora brevicauda sp. n. (Fig. 2)

Mas. Pronotum duplo longius quam latius, lobis deflexis rotundatim insertis, perpendicularibus, multo longioribus quam altioribus, antice vix obtusangulatis, postice rotundatis, margine inferiore recto. Elytra latitudine quam longitudo pronoti valde angustiore, vena mediastina destituta. Alae apicem elytrorum valde superantes. Segmentum abdominale primum margine postico in medio elevato. Segmentum nonum in medio rotundatim elevato-cristatum, margine postico triangulariter obtuse producto. Cerci breves, crassi, intus prope extremitatem excavati, apice dilatato et introrsum curvato, antice quam postice angustiore et minutissime nigro dentato. Lamina subgenitalis bilobulata, in medio carinata, a extremitate cercorum valde remota.

Longitudo corporis $\ldots \ldots \ldots \ldots \ldots, 16 \mathrm{~mm}$

Longitudo pronoti $\ldots \ldots \ldots \ldots \ldots \ldots, 4,5 \mathrm{~mm}$

Longitudo elytrorum .......... 23,0 mm

Latitudo elytrorum ............. $3,5 \mathrm{~mm}$

Longitudo femorum posticorum ... 21,0 mm

Tipo: Um macho do Departamento de Zoologia, sem qualquer indicação de procedência ou colecionador. Trata-se de um exemplar velho, descolorido, com a maior parte dos élitros de côr verde e o resto do corpo de côr castanha ou mais ou menos acinzentada.

Difere da espécie precedente pelos élitos destituidos de veia mediastina, pela elevação posterior do primeiro segmento abdominal, pelos cercos e sobretudo pela forma do último segmento do abdômen.

\section{Hyperophora brevithorax sp. n. (Fig. 3)}

Mas. Caput a margine antico pronoti modice strangulatum, vertice rotundato, paulo prominenti. Pronotum disco plano quadrangulari, sexqui longiore quam latiore, in medio vix lineato, lobis deflexis angulatim insertis, modice obliquis, antice subrectangulatis, postice rotundatis, margine inferiore obtusissime angulato. Latitudo elytrorum quam longitudo pronoti major. Vena mediastina brevissima. Alae extremitatem elytrorum valde superantes. Segmentum abdominale dorsale primum postice in medio modice angulato-elevatum. Segmentum 
nonum superne rotundatim carinatum, margine postico obtusangulato. Lamina subgenitalis modice emarginata. Cerci crassi, breves, cylindro-conici, vix incurvi, prope extremitatem attenuati et introrsum angulatim directi, apice dilatato, antice et postice minutissime dentato.

Femina. Maris similis. Pronotum lobis deflexis perpendicularibus, postice magis rotundatis, margine inferiore recto. Elytra longiora. Vena mediastina deest. Ovipositor fortiter incurvus, compressus, nitidus, ferrugineo punctatus, antice et postice acute dentatus.

\begin{tabular}{lrrr} 
& \multicolumn{1}{c}{ Mas } & Femina \\
Longitudo corporis $\ldots \ldots$ & $13,0 \mathrm{~mm}$ & $15,5 \mathrm{~mm}$ \\
Longitudo pronoti ....... & $3,0 \mathrm{~mm}$ & $4,0 \mathrm{~mm}$ \\
Longitudo elytrorum $\ldots$. & $24,0 \mathrm{~mm}$ & $30,0 \mathrm{~mm}$ \\
Latitudo elytrorum ..... & $4,5 \mathrm{~mm}$ & $5,0 \mathrm{~mm}$ \\
Longitudo femorum post. & $21,2 \mathrm{~mm}$ & $22,0 \mathrm{~mm}$ \\
Longitudo .ovipositoris .... & & $5,5 \mathrm{~mm}$
\end{tabular}

Pátria: Vila Nova, Bahia (macho); Cantareira, S. Paulo (fêmea).

Col.: E. Garbe, 1908 (macho) ; Lü̈derwald, 17-IV-1910 (fêmea).

Tipos: Um macho e uma fêmea pertencentes ao Departamento de Zoologia, presentemente com o autor.

Os tipos são muito velhos e desbotados apresentando-se de côr castanho-acinzentada, com vestígios de verde nos élitros.
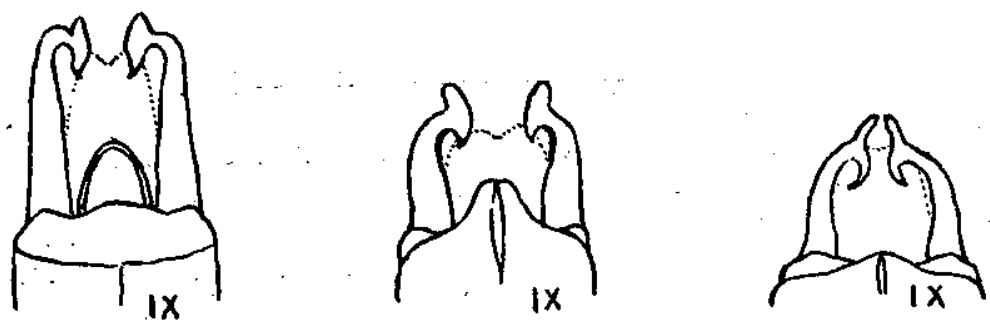

Figs, 1, 2 e 8

Ertremidade do abdômen respectivamente de Hyporophora simplicicauda, Hypercphora brevicauda e Hyperophora brevithorax 